\title{
How Much Do We Know about the Biopsychosocial Predictors of Glycaemic Control? Age and Clinical Factors Predict Glycaemic Control, but Psychological Factors Do Not
}

\author{
Mohammad Farris Iman Leong Bin Abdullah (D), ${ }^{1}$ Hatta Sidi, ${ }^{2}$ Arun Ravindran, ${ }^{3}$ \\ Paula Junggar Gosse, ${ }^{4}$ Emily Samantha Kaunismaa, ${ }^{4}$ Roslyn Laurie Mainland, ${ }^{4}$ \\ Norlaila Mustafa, ${ }^{5}$ Nurul Hazwani Hatta, ${ }^{6}$ Puteri Arnawati, ${ }^{6}$ Amelia Yasmin Zulkifli, ${ }^{6}$ \\ and Luke Sy-Cherng Woon (D) $^{2}$ \\ ${ }^{1}$ Advanced Medical and Dental Institute, Universiti Sains Malaysia, Malaysia \\ ${ }^{2}$ Department of Psychiatry, Universiti Kebangsaan Malaysia Medical Centre, Malaysia \\ ${ }^{3}$ Centre for Addiction and Mental Health, University of Toronto, Canada \\ ${ }^{4}$ Faculty of Medicine, University of Toronto, Canada \\ ${ }^{5}$ Department of Medicine, Universiti Kebangsaan Malaysia Medical Centre, Malaysia \\ ${ }^{6}$ University of Galway, Ireland
}

Correspondence should be addressed to Luke Sy-Cherng Woon; lukewoon@ukm.edu.my

Received 15 November 2019; Accepted 22 April 2020; Published 5 May 2020

Academic Editor: Ed Randell

Copyright ( 2020 Mohammad Farris Iman Leong Bin Abdullah et al. This is an open access article distributed under the Creative Commons Attribution License, which permits unrestricted use, distribution, and reproduction in any medium, provided the original work is properly cited.

Objective. Diabetes mellitus is one of the most common noncommunicable diseases in Malaysia. It is associated with significant complications and a high cost of treatment, especially when glycaemic control is poor. Despite its negative impact on health, data is still lacking on the possible biopsychosocial predictors of poor glycaemic control among the diabetic population. This study is aimed at determining the prevalence of poor glycaemic control as well as its association with biopsychosocial factors such as personality traits, psychiatric factors, and quality of life (QOL) among Malaysian patients with diabetes. Methods. A cross-sectional study was conducted at the Universiti Kebangsaan Malaysia Medical Centre (UKMMC) using outpatient population diabetic patients. Demographic data on social and clinical characteristics were collected from participants. Several questionnaires were administered, including the Beck Depression Inventory-II (BDI-II) to measure depressive symptoms, the Generalized Anxiety Disorder-7 (GAD-7) to assess anxiety symptoms, the Big Five Inventory (BFI) to evaluate personality traits, and the WHO Quality of Life-BREF (WHOQOL-BREF) to assess QOL. Multivariate binary logistic regression was performed to determine the predictors of poor glycaemic control. Results. 300 patients with diabetes mellitus were recruited, with the majority (90\%) having type 2 diabetes. In this population, the prevalence of poor glycaemic control $\left(\mathrm{HbA}_{1 \mathrm{C}} \geq 7.0 \%\right)$ was $69 \%$, with a median $\mathrm{HbA}_{1 \mathrm{C}}$ of $7.6 \%(\mathrm{IQR}=2.7)$. Longer duration of diabetes mellitus and a greater number of days of missed medications predicted poor glycaemic control, while older age and overall self-perception of QOL protected against poor glycaemic control. No psychological factors were associated with poor glycaemic control. Conclusion. This study emphasizes the importance of considering the various factors that contribute to poor glycaemic control, such as duration of diabetes, medication adherence, age, and QOL. These findings should be used by clinicians, particularly when planning a multidisciplinary approach to the management of diabetes. 


\section{Introduction}

Diabetes mellitus is one of the most common chronic diseases worldwide, affecting 422 million people in 2014. It is expected to increase in prevalence, with an estimated 629 million people affected by 2045 [1]. While diabetes is a worldwide health crisis, the prevalence of diabetes is increasing at a more rapid rate in lower- and middle-income countries [2]. Patients in these countries often have limited access to healthcare resources, potentially exacerbating both their diabetes and its associated comorbidities [3]. Furthermore, much of the research on diabetes as it relates to biopsychosocial factors has been conducted in higher-income countries, despite the strong need to understand these relationships in lower- and middle-income countries where individuals often face significant barriers to care. As such, this study was conducted in Malaysia, a middle-income country where the estimated prevalence of diabetes is $17.5 \%$ [2], over $10 \%$ higher than the global average [4].

In Malaysia, diabetes mellitus is currently the second most common noncommunicable disease. The prevalence of diabetes increases with age, ranging from $5.5 \%$ in the $18-$ 19 -year age group to $39.1 \%$ in the $70-74$-year age group [5]. In 2011, the estimated cost of managing diabetes in the country was 2.04 billion Malaysian ringgits (493 million USD), while the estimated cost per patient was approximately RM 68,000 (16,000 USD) [6]. Hence, there is significant economic burden associated with the management of diabetes mellitus in Malaysia.

Diabetic complications can be divided into macrovascular and microvascular complications which worsen over time if optimal glycaemic control is not achieved. Among the diabetic population in Malaysia, microvascular complications, such as nephropathy (7.8\%) and retinopathy (6.7\%), are common. Macrovascular complications are less common and include ischaemic heart disease (5.3\%), cerebrovascular incidents (1.3\%), and diabetic foot ulcers (1.2\%) which can lead to amputations (0.9\%). According to the 2009-2012 National Diabetes Registry of Malaysia, diabetic complications are underestimated due to a high proportion of missing data [7]. In fact, a recent review of Malaysian statistics on diabetes suggests that the true prevalence of microvascular complications is closer to $75 \%$ and macrovascular complications is closer to $29 \%$ [8]. It is therefore important to explore factors that predict glycaemic control so that treatment strategies can be designed to effectively manage diabetes and its complications.

In the context of the biopsychosocial model, data is lacking on the predictors of glycaemic control in the Malaysian population. Only a few previous studies on Malaysian patients with diabetes have reported associations between biopsychosocial factors and poor glycaemic control. These studies reported that the following factors are significantly associated with poor glycaemic control: older age (60-69 years old), being identified as Malay or Indian, having a duration of diabetes $\geq 5$ years, the use of oral hypoglycaemic agents and insulin, comorbid hypertension and hyperlipidaemia, and patient perception that diabetes interferes with daily activities. Being unemployed or retired and having up to tertiary education are all protective factors against poor glycaemic control. Psychiatric disorders, such as depression and anxiety, have not been found to be predictive of glycaemic control in Malaysian diabetic patients [9-11]. However, personality traits, such as type D personality (social inhibition, negative affectivity, and neuroticism), have previously been associated with diabetes mellitus [12]. As far as we are aware, no study has assessed the relationships between personality traits, quality of life (QOL), and glycaemic control in Malaysian patients with diabetes. To address this research gap, the Anxiety, Depression, and Personality Traits in Diabetes Mellitus (ADAPT-DM) study is aimed at determining the prevalence of poor glycaemic control as well as its relationship with biopsychosocial factors, including personality traits, psychiatric factors, and QOL among diabetic patients.

\section{Materials and Methods}

2.1. Study Participants and Setting. The ADAPT-DM study was a cross-sectional study which recruited patients who were diagnosed with diabetes mellitus. The study was approved by the Medical Research Committee of the Faculty of Medicine, Universiti Kebangsaan Malaysia (UKM FPR.SPI 800-2/28/166/FF-2019-342). The participants were recruited via convenience sampling from the outpatient endocrine clinic of Universiti Kebangsaan Malaysia Medical Centre (UKMMC). Patients were eligible if they were at least 18 years old and had a known diagnosis of diabetes mellitus (type 1, type 2, or gestational diabetes mellitus). Patients were excluded if they presented with cognitive impairment or with psychotic symptoms. During the two-month enrolment period, patients who met the eligibility criteria were invited to participate in the study. Patients were presented with a consent form and an oral briefing in their preferred language (Malay or English). Information that was provided included study objectives, length, risks and benefits of participation, measures to maintain confidentiality, and participant rights and responsibilities. Respondents who provided written consent to participate were asked to complete all components of the study to ensure study quality.

2.2. Data Collection. Participants were asked to complete six standardized questionnaires under the supervision of a researcher. The demographic data collected included age, gender, ethnicity, marital status, employment, education, monthly income, and religion. The social data collected included self-perceived social support, diet, exercise, cigarette smoking, recreational drug use, and alcohol use. Clinical data were also obtained, including type of diabetes mellitus, duration of diabetes, number of medications, insulin therapy, selfperceived diabetic control, and comorbid hypertension, dyslipidaemia, renal disease, ischaemic heart disease, cancer, and cerebrovascular incident. The weight, height, and body mass index (BMI) of the participants were also obtained. A BMI of 18.5 to 24.95 was considered normal, 25.05 to 29.95 was considered overweight, and $\geq 30.05$ was considered obese [13]. The clinical data collected were supplemented with information available from each participant's electronic medical record. This included blood test results processed in the 
ISO-certified laboratory of UKMMC, such as most recent haemoglobin $\mathrm{A}_{1 \mathrm{C}}\left(\mathrm{HbA}_{1 \mathrm{C}}\right)$, fasting blood glucose, blood urea nitrogen (BUN), creatinine, liver function tests, and lipid profile. An $\mathrm{HbA}_{1 \mathrm{C}}$ of $\geq 7.0 \%$ was used as an indicator of poor diabetic control [14]. In addition, four validated questionnaires were administered to participants. Depressive symptoms were assessed using a validated Malaysian version of the Beck Depression Inventory-II (BDI-II); anxiety symptoms were evaluated with the Generalized Anxiety Disorder-7 (GAD-7); personality traits were assessed with the Big Five Inventory (BFI); and quality of life was evaluated with the World Health Organization Quality of Life-BREF (WHOQOL-BREF).

\subsubsection{Generalized Anxiety Disorder-7 (GAD-7). The GAD-7} is a self-rated screening tool and a severity indicator for generalized anxiety disorder (GAD) in the primary health care setting. It consists of seven items, each of which is rated on a 4-point Likert scale ranging from 0 (not at all) to 3 (nearly every day). As such, possible total scores range from 0 to 21 , with higher scores indicating greater severity of GAD symptoms. The tool has a diagnostic cut-off point of 10 , with a sensitivity of $89 \%$ and a specificity of $82 \%$ [15]. It has good psychometric properties with good internal consistency (Cronbach's $\alpha$ of 0.85) [16]. The Malay version of the GAD-7 has also demonstrated good psychometric properties with an acceptable internal consistency (Cronbach's $\alpha$ of 0.74) [17].

2.2.2. Beck Depression Inventory-II (BDI-II). The BDI was initially developed by Aaron Beck to assess cognitive symptoms of depression. It later incorporated somatic symptoms of depression to better reflect DSM criteria. The BDI-II is a self-administered questionnaire and consists of 21 items with total scores ranging from 0 to 63, with each item being scored from 0 to 3 . Higher scores indicate greater severity of depressive symptoms. The BDI-II is reported to have excellent internal consistency with Cronbach's $\alpha$ of 0.90 [18]. The twenty-question Malay version of the BDI-II is also reported to have good psychometric properties, with good internal consistency (Cronbach's $\alpha$ of 0.80) [19].

2.2.3. Big Five Inventory (BFI). The BFI is a 44 -item, selfrated tool used for assessing personality traits. The inventory's items are designed to measure five main domains: neuroticism $(\mathrm{N} ; 8$ items), openness to experience $(\mathrm{O} ; 10$ items), extraversion (E; 8 items), conscientiousness (C; 9 items), and agreeableness (A; 9 items). Each item is measured using a 5-point Likert scale, ranging from 1 (strongly disagree) to 5 (strongly agree). The BFI has good psychometric properties with good internal consistency (Cronbach's $\alpha$ average above 0.80 ) [20]. The Malay version of the BFI has also demonstrated good psychometric properties with good reliability (Hancock and Mueller's coefficient $\mathrm{H}$ ranging from 0.70 to 0.77 for all domains except for openness which had a coefficient $\mathrm{H}$ of 0.60 , which may be a result of cultural differences in how openness is conceptualized) [21].
2.2.4. The World Health Organization Quality of Life-BREF (WHOQOL-BREF). The WHOQOL-BREF is a 26-item, self-rated tool used to evaluate the quality of life. The first two items assess the overall perception of QOL and overall perception of health, while the remaining 24 items measure specific domains of the quality of life: physical health QOL (7 items), psychological QOL (6 items), social QOL (3 items), and environmental QOL ( 8 items). Each item is scored with a 5 -point Likert scale ranging from 1 (very poor) to 5 (very good). Three items (items 3, 4, and 26) are also negatively phrased, and hence, their scores are reversed when computing the total domain scores. The total score of each domain is then converted to a transformed score ranging from 4 to 20. The WHOQOL-BREF has good psychometric properties with internal consistency ranging from Cronbach's $\alpha$ of 0.55 to 0.89 , and it has been found to be a valid and reliable alternative to the WHOQOL-100 for measuring QOL [22]. The Malay version of the WHOQOL-BREF has also demonstrated excellent psychometric properties with good internal consistency (Cronbach's $\alpha$ of 0.89) [23].

2.3. Statistical Analysis. All statistical analyses were performed using SPSS version 20 (SPSS Inc., Chicago, IL). Descriptive statistics were computed for demographic characteristics, lifestyle, social history, clinical factors, and the BFI, BDI-II, GAD-7, and WHOQOL-BREF scores. Categorical variables were described in frequency and percentage. Since the normality test indicated that the continuous variables were not normally distributed, these variables were reported in median and interquartile range (IQR). We first conducted the binary logistic regression analysis to evaluate the crude odds ratios (crude ORs) of the demographic characteristics, lifestyle behaviour, social history, clinical factors, and the BFI, BDI-II, GAD-7, and WHOQOL-BREF scores in predicting the outcome of diabetic control (good/poor). Then, variables with significant crude odds ratios (crude ORs, $p<0.05)$ were entered into a multivariate logistic regression model to assess the association of these variables with diabetic control by computing the adjusted odds ratios (adjusted ORs). Two-tailed tests were used, and a $p$ value of $<0.05$ was considered statistically significant.

\section{Results}

3.1. Characteristics of Study Participants. The study recruited 300 participants, most of whom were in the elderly age group (median age $=63$ years, IQR $=16$ years). There were slightly more male participants (53\%) than female (47\%). Approximately two-thirds of the participants were Malay (65\%), while the rest were either Chinese (18\%) or another ethnic group (17\%). The majority of participants were Muslim (66\%), and a large proportion were married (77\%). $84 \%$ of the participants completed at least a secondary education, although the majority of them were retired $(72 \%)$. More than half $(55.3 \%)$ of the participants reported living in a lowincome household (monthly income $<$ RM 3000 ), likely due to the high proportion of participants who were retired.

Most participants were nonsmokers (93\%), did not consume alcohol (90\%), had no history of illicit drug use 
(98\%), and reported having good social support (80\%). Most patients had type 2 diabetes $(90 \%)$, with only a small minority having type 1 diabetes (7\%) or gestational diabetes $(2 \%)$. The median duration of diabetes was 14 years $(\mathrm{IQR}=12$ years). All patients were on oral hypoglycaemic medications, and most patients were on multiple medications (median number of medications taken $=6$ types, $\mathrm{IQR}=3$ types $)$. Nearly half $(46 \%)$ of the patients were on insulin therapy. $69 \%$ of the participants had poor diabetic control (median $\mathrm{HbA}_{1 \mathrm{C}}=7.6 \%, \mathrm{IQR}=2.7$; median fasting blood glucose $=$ $7.6 \mathrm{mmol} / \mathrm{L}, \mathrm{IQR}=2.7$ ), although $71 \%$ of participants perceived that they had either good or very good diabetic management. Comorbid medical conditions were also common among participants, with $74 \%$ having hypertension, $51 \%$ having dyslipidaemia, $27 \%$ having ischaemic heart disease, $18 \%$ having renal disease, and $9 \%$ having previously experienced a cerebrovascular incident. The median BMI was 27.6 (IQR = 6.6), which was considered overweight. The demographic, social, and clinical characteristics of the participants are summarized in Table 1.

The BDI-II and GAD-7 results indicated that $20 \%$ of the participants had depression and $9 \%$ had anxiety. Assessment with the BFI revealed that the median domain scores were as follows: extraversion was $3.4(\mathrm{IQR}=0.8)$, agreeableness was $3.8(\mathrm{IQR}=0.4)$, conscientiousness was $3.7(\mathrm{IQR}=0.6)$, neuroticism was $2.5(\mathrm{IQR}=0.7)$, and openness to experience was $3.5(\mathrm{IQR}=0.6)$. As for the WHOQOL-BREF scores, the median score for overall perception of QOL was 4.0 $(\mathrm{IQR}=4.0)$, while the median score for overall perception of health was $3.0(\mathrm{IQR}=3.0)$. The median score for physical health QOL was $14.3(\mathrm{IQR}=3.4)$, psychological QOL was $15.3(\mathrm{IQR}=2.7)$, social QOL was $16.0(\mathrm{IQR}=2.7)$, and environmental QOL was $15.0(\mathrm{IQR}=2.5)$. The psychological characteristics and QOL of the participants are summarized in Table 2.

3.2. Predictors of Poor Glycaemic Control. In unadjusted binary logistic regression analyses, the variables significantly associated with poor glycaemic control included the following: a secondary education or higher (crude OR $=2.33,95 \%$ $\mathrm{CI}=1.15-4.72$ ), longer duration of diabetes mellitus (crude $\mathrm{OR}=1.05,95 \% \mathrm{CI}=1.02-1.08)$, taking three or more diabetic medications (crude $\mathrm{OR}=3.11,95 \% \mathrm{CI}=1.32-7.30$ ), and greater number of days of missed medications (crude $\mathrm{OR}=1.39,95 \% \mathrm{CI}=1.11-1.73)$. On the contrary, older age (crude $\mathrm{OR}=0.97,95 \% \mathrm{CI}=0.95-0.99$ ), absence of insulin therapy (crude $\mathrm{OR}=0.32,95 \% \mathrm{CI}=0.19-0.55$ ), and better overall perception of $\mathrm{QOL}$ (crude $\mathrm{OR}=0.60$, $95 \% \mathrm{CI}=0.42-0.86$ ) were protective against poor glycaemic control. None of the personality traits, psychiatric factors, or any other domains of QOL were associated with poor glycaemic control.

After adjusting for confounding variables in multivariate logistic regression analysis, there remained only two variables which predicted poor glycaemic control: longer duration of diabetes mellitus (adjusted $\mathrm{OR}=1.11,95 \% \mathrm{CI}=1.06-1.16$ ) and greater number of days of missed medications (adjusted $\mathrm{OR}=1.78,95 \% \mathrm{CI}=1.21-2.61)$. In contrast, older age (adjusted OR $=0.95,95 \% \mathrm{CI}=0.91-0.98$ ) and better overall perception of QOL (adjusted OR $=0.37$, 95\% CI $=0.20$ 0.67) were protective against poor glycaemic control. Table 3 summarizes the crude and adjusted ORs of the various factors in predicting poor glycaemic control.

\section{Discussion}

The aim of this study was to determine the prevalence of poor glycaemic control among Malaysian diabetic patients and its association with biopsychosocial factors, such as personality traits, psychiatric factors, and QOL. We found that $69 \%$ of patients had poor glycaemic control. This is similar to the prevalence reported by studies of diabetic patients in China, Ghana, Malaysia, and Egypt, which ranges from $50.3 \%$ to $74.3 \%[11,24-26]$.

There were only two factors found to be predictive of poor glycaemic control: longer duration of diabetes mellitus, which increased the odds of poor glycaemic control by 1.1 fold, and greater number of days of missed medication, which increased the odds of poor glycaemic control by 1.8fold. These findings support existing evidence from previous studies that suggest diabetic control worsens with increasing duration of diabetes mellitus [9, 24-27]. In fact, a duration of diabetes of $\geq 5$ years has been shown to increase the risk of poor glycaemic control in type 2 diabetic patients $[9,27]$. The median duration of diabetes in our study was 14 years. In patients with diabetes mellitus, the number and functioning of pancreatic $\beta$-cells deteriorate over time, leading to an increase in insulin resistance and a reduction in insulin secretion. This results in increasing difficulty in maintaining glycaemic control, which may explain why a longer duration of diabetes is associated with poorer glycaemic control [28]. The association between poor diabetic medication adherence and poor glycaemic control is consistent with two studies conducted in Tanzania and Ethiopia [29, 30]. It has been found that the pain and anxiety associated with daily insulin injections may increase the risk of insulin omission in diabetic patients $[31,32]$. Since almost half of our participants were on insulin therapy (46\%), this may have contributed to a lack of medication adherence and, thus, poor glycaemic control. In keeping with this, the absence of insulin therapy was shown to be an independent protective factor against poor glycaemic control in this study (crude $\mathrm{OR}=0.32$ ). Our findings highlight the importance of patient education and counselling in the management of diabetes mellitus, as a lack of understanding may lead to poor medication adherence. In order to encourage insulin adherence, patients need to appreciate the rationale for insulin therapy and the importance of regular follow-up for dose titrations.

Our study further identified two protective factors against poor glycaemic control: older age and a better overall perception of QOL. This first finding is consistent with several previous studies that have reported an association between older age and better glycaemic control [25, 33-36]. There is evidence that younger patients may be prescribed lower dosages of medication [33]. This could be a contributing factor as to why older patients have better glycaemic control compared to their younger counterparts. As far as we are aware, our study is the first to report that patients with better 
TABLE 1: Demographic, social, and clinical characteristics of the participants.

\begin{tabular}{|c|c|c|}
\hline Variables & Participants $(n)$ & Percentage (\%) \\
\hline Age & 63 years $^{\mathrm{a}}$ & $16^{\mathrm{b}}$ \\
\hline \multicolumn{3}{|l|}{ Gender: } \\
\hline Male & 158 & 52.7 \\
\hline Female & 141 & 47.0 \\
\hline Missing & 1 & 0.3 \\
\hline \multicolumn{3}{|l|}{ Ethnicity: } \\
\hline Malays & 195 & 65.0 \\
\hline Non-Malays & 105 & 35.0 \\
\hline \multicolumn{3}{|l|}{ Marital status: } \\
\hline Married & 231 & 77.0 \\
\hline Single/divorce/widow/widower & 67 & 22.3 \\
\hline Missing & 2 & 0.7 \\
\hline \multicolumn{3}{|l|}{ Education status: } \\
\hline No education/primary education & 45 & 15.0 \\
\hline Secondary education & 133 & 44.3 \\
\hline Tertiary education & 119 & 39.7 \\
\hline Missing & 3 & 1.0 \\
\hline \multicolumn{3}{|l|}{ Employment status: } \\
\hline Employed & 80 & 26.7 \\
\hline Retired/unemployed & 217 & 72.3 \\
\hline Missing & 3 & 1.0 \\
\hline \multicolumn{3}{|l|}{ Monthly income: } \\
\hline$<$ Ringgit Malaysia (RM) 3,000 & 166 & 55.3 \\
\hline$\geq$ Ringgit Malaysia (RM) 3,000 & 118 & 39.3 \\
\hline Missing & 16 & 5.3 \\
\hline \multicolumn{3}{|l|}{ Religion: } \\
\hline Islam & 199 & 66.3 \\
\hline Other religions & 99 & 33.0 \\
\hline Missing & 2 & 0.7 \\
\hline \multicolumn{3}{|l|}{ Cigarette smoking: } \\
\hline Nonsmoker & 280 & 93.3 \\
\hline Smoker & 20 & 6.7 \\
\hline \multicolumn{3}{|l|}{ Alcohol use: } \\
\hline Yes & 26 & 8.7 \\
\hline No & 271 & 90.3 \\
\hline Missing & 3 & 1.0 \\
\hline \multicolumn{3}{|l|}{ Recreational drug use: } \\
\hline Yes & 5 & 1.7 \\
\hline No & 294 & 98.0 \\
\hline Missing & 1 & 0.3 \\
\hline \multicolumn{3}{|l|}{ Self-perceived social support: } \\
\hline Poor & 18 & 6.0 \\
\hline Moderate & 48 & 16.0 \\
\hline Good & 233 & 77.7 \\
\hline Missing & 1 & 0.3 \\
\hline \multicolumn{3}{|l|}{ Types of diabetes mellitus: } \\
\hline Gestational diabetes & 6 & 2.0 \\
\hline Type 1 diabetes & 22 & 7.3 \\
\hline
\end{tabular}


TABLE 1: Continued.

\begin{tabular}{|c|c|c|}
\hline Variables & Participants $(n)$ & Percentage (\%) \\
\hline Type 2 diabetes & 269 & 89.7 \\
\hline Missing & 3 & 1.0 \\
\hline $\mathrm{HbA}_{1 \mathrm{C}}$ & $7.6^{\mathrm{a}}$ & $2.7^{\mathrm{b}}$ \\
\hline Fasting blood glucose & $7.1^{\mathrm{a}}$ & $3.4^{\mathrm{b}}$ \\
\hline Duration of diabetes mellitus & 14 years $^{\mathrm{a}}$ & 12 years $^{\mathrm{b}}$ \\
\hline Number of medications taken & 6 types $^{\mathrm{a}}$ & 3 types $^{b}$ \\
\hline Number of diabetic medications taken & 2 types $^{\mathrm{a}}$ & 1 type $^{\mathrm{b}}$ \\
\hline \multicolumn{3}{|l|}{ Insulin therapy: } \\
\hline Yes & 138 & 46.0 \\
\hline No & 114 & 38.0 \\
\hline Missing & 48 & 16.0 \\
\hline Frequency of clinic visits per year & $2^{\mathrm{a}}$ & $2^{\mathrm{b}}$ \\
\hline Number of days of missed medications & $0^{\mathrm{a}}$ & $0^{\mathrm{b}}$ \\
\hline Number of days of reduced medication intake & $0^{\mathrm{a}}$ & $0^{\mathrm{b}}$ \\
\hline \multicolumn{3}{|l|}{ Self-perceived diabetic control: } \\
\hline Poor & 15 & 5.0 \\
\hline Moderate & 70 & 23.3 \\
\hline Good & 214 & 71.3 \\
\hline Missing & 1 & 0.3 \\
\hline \multicolumn{3}{|l|}{ Diabetic control: } \\
\hline Good $\left(\mathrm{HbA}_{1 \mathrm{C}}<7.0 \%\right)$ & 92 & 30.7 \\
\hline Poor $\left(\mathrm{HbA}_{1 \mathrm{C}} \geq 7.0 \%\right)$ & 208 & 69.3 \\
\hline \multicolumn{3}{|l|}{ Comorbid medical illnesses: } \\
\hline Hypertension & 222 & 74.0 \\
\hline Hypercholesterolemia & 152 & 50.7 \\
\hline Ischaemic heart diseases & 82 & 27.3 \\
\hline Cerebrovascular incidents & 27 & 9.0 \\
\hline Renal diseases & 53 & 17.7 \\
\hline \multicolumn{3}{|l|}{ Obesity status: } \\
\hline No (body mass index $<25$ ) & 65 & 21.7 \\
\hline Overweight (body mass index between 25.0 and 29.9) & 91 & 30.3 \\
\hline Obese (body mass index $\geq 30$ ) & 78 & 26.0 \\
\hline Missing & 66 & 22.0 \\
\hline Body mass index (BMI) & $27.6^{\mathrm{a}}$ & $6.6^{\mathrm{b}}$ \\
\hline
\end{tabular}

${ }^{\mathrm{a}}$ Median. ${ }^{\mathrm{b}}$ Interquartile range (IQR).

overall perception of QOL had an almost two thirds reduced odds of having poor glycaemic control. A strong sense of selfefficacy has been shown to be predictive of better self-care behaviours, better diabetic control, and greater QOL in patients with chronic illnesses $[37,38]$. In our participants, self-efficacy may be a mediating factor in the relationship between perceived quality of life and glycaemic control. It would be beneficial to assess self-efficacy in this population in future studies.

Surprisingly, our findings demonstrated that psychiatric factors, namely, depression and anxiety, were not associated with glycaemic control. This contradicts the findings from two previous studies: a meta-analysis of 775 studies of diabetic patients and a literature review which indicated that depression predicts lower adherence to physical activity and dietary control and, hence, poorer glycaemic control $[39,40]$. However, de Groot et al. reported that the effect size of depression in predicting poor glycaemic control is small, which may explain why depression was not a significant predictor of poor glycaemic control in our study. Conversely, our finding that anxiety is not predictive of poor glycaemic control is in line with the findings of a meta-analysis by Brown et al. in 2016 and a literature review by de Groot et al. in 2016.

Our findings also demonstrated that personality traits were not associated with poor glycaemic control. In the current literature, there exists mixed evidence regarding the relationship between personality traits and glycaemic control. In 2017, Novak et al. studied 117 couples with diabetes and demonstrated that neuroticism reduces dietary and exercise 
TABLe 2: Psychological characteristics and quality of life of the participants.

\begin{tabular}{lcc}
\hline Variables & Participants $(n)$ & Percentage (\%) \\
\hline Anxiety disorders (assessed by the GAD-7): & & 9.0 \\
Yes & 27 & 91.0 \\
No & & 20.0 \\
Depressive disorders (assessed by the BDI): & 60 & 80.0 \\
Yes & 240 & $0.8^{\mathrm{b}}$ \\
No & & $0.4^{\mathrm{b}}$ \\
Big Five Inventory (BFI) scores: & $3.4^{\mathrm{a}}$ & $0.6^{\mathrm{b}}$ \\
Extraversion & $3.8^{\mathrm{a}}$ & $0.7^{\mathrm{b}}$ \\
Agreeableness & $3.7^{\mathrm{a}}$ & $0.6^{\mathrm{b}}$ \\
Conscientiousness & $2.5^{\mathrm{a}}$ & \\
Neuroticism & $3.3^{\mathrm{a}}$ & $4.0^{\mathrm{b}}$ \\
Openness & & $3.0^{\mathrm{b}}$ \\
WHOQOL-BREF scores: & $4.0^{\mathrm{a}}$ & $3.4^{\mathrm{b}}$ \\
Overall perception of QOL & $3.0^{\mathrm{a}}$ & $2.7^{\mathrm{b}}$ \\
Overall perception of health & $14.3^{\mathrm{a}}$ & $2.7^{\mathrm{b}}$ \\
Physical health QOL & $15.3^{\mathrm{a}}$ & $2.5^{\mathrm{b}}$ \\
Psychological QOL & $16.0^{\mathrm{a}}$ & $15.0^{\mathrm{a}}$ \\
Social QOL & & \\
Environmental QOL & & \\
\hline
\end{tabular}

${ }^{\mathrm{a}}$ Median. ${ }^{\mathrm{b}}$ Interquartile range (IQR).

adherence and is therefore associated with lower diabetic efficacy [41]. Similarly, an Iranian study of type 2 diabetic patients reported neuroticism to be positively correlated with poor glycaemic control, while extraversion and conscientiousness were inversely correlated [42]. In addition, an Australian study of type 1 diabetic patients also reported that conscientiousness and agreeableness are significant predictors of good glycaemic control [43]. On the other hand, other studies specifically using the fivefactor model of personality have found that there is no independent association between personality traits and glycaemic control $[44,45]$. In line with these latter findings, we found that none of the big five personality traits were associated with glycaemic control. This discrepancy in the current literature may be a result of differences in the number of variables used in each study. For example, unlike our study, the first three aforementioned studies did not include demographic, social, and clinical factors as confounding factors. When demographic, social, and clinical factors are taken into account, personality traits do not appear to significantly predict glycaemic control.

Our findings need to be interpreted in light of a few limitations. The main limitation is the cross-sectional nature of the study, which prevents us from drawing any conclusions about causality between the various factors measured and glycaemic control. Second, multiple variables were tested for associations in this study, and this multiplicity may raise the possibility of false positives due to type 1 error [46]. While new strategies have been proposed to handle the issue of multiple testing [47], there are also strong arguments that it is not necessary to adjust for multiple comparisons in observational epidemiological studies [48]. In addition, this study was conducted in the setting of a tertiary healthcare centre based in Kuala Lumpur; therefore, the findings of this study may not be generalizable to the entire Malaysian diabetic population. We recommend that a prospective study with multicentre subject recruitment must be conducted in the future to confirm our findings. Finally, missing data may lead to a bias in the study findings; however, the proportion of missing data was small for most of the variables assessed except for monthly income $(5.3 \%$ missing $)$ and insulin therapy (16\% missing).

Despite the limitations listed above, this study provides clinicians with comprehensive data on the biopsychosocial predictors of poor glycaemic control. These are important considerations when planning a multidisciplinary approach to diabetic management in the Malaysian context. To our knowledge, this is also the first study in Malaysia to evaluate the predictive effects of personality and quality of life on glycaemic control. It highlights the need for effective diabetes education in order to improve medication adherence, and it cautions healthcare providers to anticipate the negative effects associated with a longer disease duration. Our findings also emphasize the importance of assessing patients' perception of their QOL, as this appears to be associated with glycaemic control. A greater emphasis should be placed on evaluating the barriers to optimal glycaemic control, especially among younger patients. We hope that this study serves as a reminder for healthcare providers to evaluate glycaemic control in the greater context of each patient's life, as there are a number of biopsychosocial factors that may contribute to a patient's management of his or her diabetes. 
TABLE 3: Factors associated with poor glycaemic control among the participants.

\begin{tabular}{|c|c|c|c|c|}
\hline Variables & Unadjusted OR (95\% CI) & $p$ value & Adjusted OR (95\% CI) & $p$ value \\
\hline Age & $0.97(0.95-0.99)$ & $0.002^{*}$ & $0.95(0.91-0.98)$ & $0.002^{*}$ \\
\hline \multicolumn{5}{|l|}{ Gender: } \\
\hline Male & 1 & & & \\
\hline Female & $0.75(0.46-1.22)$ & 0.24 & - & - \\
\hline \multicolumn{5}{|l|}{ Ethnicity: } \\
\hline Malays & 1 & & & \\
\hline Non-Malays & $1.13(0.68-1.89)$ & 0.64 & - & - \\
\hline \multicolumn{5}{|l|}{ Marital status: } \\
\hline Married & 1 & & & \\
\hline Single/divorce/widow/widower & $1.72(0.98-3.04)$ & 0.59 & - & - \\
\hline \multicolumn{5}{|l|}{ Education status: } \\
\hline No education/primary education & 1 & 1 & & \\
\hline Secondary education & $2.33(1.15-4.72)$ & $0.019^{*}$ & $1.73(0.63-4.79)$ & 0.29 \\
\hline Tertiary education & $1.71(0.84-3.44)$ & 0.14 & $0.73(0.24-2.19)$ & 0.57 \\
\hline \multicolumn{5}{|l|}{ Employment status: } \\
\hline Employed & 1 & & & \\
\hline Unemployed/retired & $1.22(0.70-2.11)$ & 0.48 & - & - \\
\hline \multicolumn{5}{|l|}{ Monthly income: } \\
\hline$<$ RM 3,000 & 1 & & & \\
\hline$\geq$ RM 3,000 & $1.43(0.85-2.41)$ & 0.18 & - & - \\
\hline \multicolumn{5}{|l|}{ Religion: } \\
\hline Islam & 1 & & & \\
\hline Other religions & $1.03(0.61-1.74)$ & 0.91 & - & - \\
\hline \multicolumn{5}{|l|}{ Self-perceived social support: } \\
\hline Poor & 1 & & & \\
\hline Moderate & $0.44(0.09-2.30)$ & 0.33 & - & - \\
\hline Good & $0.50(0.11-2.36)$ & 0.38 & - & - \\
\hline \multicolumn{5}{|l|}{ Cigarette smoking: } \\
\hline Non-smoker & 1 & & & \\
\hline Smoker & $0.86(0.30-2.49)$ & 0.78 & - & - \\
\hline \multicolumn{5}{|l|}{ Alcohol use: } \\
\hline No & 1 & & & \\
\hline Yes & $1.21(0.52-2.82)$ & 0.67 & - & - \\
\hline \multicolumn{5}{|l|}{ Recreational drug use: } \\
\hline No & 1 & & & \\
\hline Yes & $0.56(0.06-5.06)$ & 0.60 & - & - \\
\hline \multicolumn{5}{|l|}{ Types of diabetes mellitus: } \\
\hline Gestational diabetes & 1 & & & \\
\hline Type 1 diabetes & $2.00(0.15-26.73)$ & 0.60 & - & - \\
\hline Type 2 diabetes & $0.42(0.05-3.64)$ & 0.43 & - & - \\
\hline Duration of diabetes mellitus & $1.05(1.02-1.08)$ & $0.002^{*}$ & $1.11(1.06-1.16)$ & $<0.001^{*}$ \\
\hline Frequency of clinic visits & $0.95(0.86-1.05)$ & 0.35 & - & - \\
\hline \multicolumn{5}{|l|}{ Comorbid hypertension: } \\
\hline No & 1 & & & \\
\hline Yes & $0.99(0.57-1.74)$ & 0.98 & - & - \\
\hline \multicolumn{5}{|l|}{ Comorbid hypercholesterolemia: } \\
\hline No & 1 & & & \\
\hline Yes & $1.03(0.63-1.67)$ & 0.92 & - & - \\
\hline
\end{tabular}


TABLe 3: Continued.

\begin{tabular}{|c|c|c|c|c|}
\hline Variables & Unadjusted OR (95\% CI) & $p$ value & Adjusted OR (95\% CI) & $p$ value \\
\hline \multicolumn{5}{|l|}{ Comorbid ischaemic heart diseases: } \\
\hline No & 1 & & & \\
\hline Yes & $1.16(0.67-1.99)$ & 0.60 & - & - \\
\hline \multicolumn{5}{|l|}{ Comorbid cerebrovascular incident: } \\
\hline No & 1 & & & \\
\hline Yes & $0.95(0.40-2.25)$ & 0.90 & - & - \\
\hline \multicolumn{5}{|l|}{ Comorbid renal diseases: } \\
\hline No & 1 & & & \\
\hline Yes & $0.87(0.45-1.68)$ & 0.68 & - & - \\
\hline \multicolumn{5}{|l|}{ Number of diabetic medications: } \\
\hline 1 type & 1 & 1 & & \\
\hline 2 types & $1.73(0.97-3.10)$ & 0.064 & $1.10(0.50-2.43)$ & 0.82 \\
\hline 3 types & $3.11(1.32-7.30)$ & $0.009^{*}$ & $1.60(0.55-4.70)$ & 0.39 \\
\hline 4 types & $5.12(0.61-42.97)$ & 0.13 & $0.90(0.07-10.91)$ & 0.93 \\
\hline \multicolumn{5}{|l|}{ Insulin therapy: } \\
\hline Yes & 1 & 1 & & \\
\hline No & $0.32(0.19-0.55)$ & $<0.001^{*}$ & $0.52(0.24-1.15)$ & 0.11 \\
\hline Number of medications taken daily & $1.00(0.91-1.10)$ & 0.96 & - & - \\
\hline Number of days of missed medication & $1.39(1.11-1.73)$ & $0.004^{*}$ & $1.78(1.21-2.61)$ & $0.003^{*}$ \\
\hline Number of days of reduced medication intake & $1.12(0.97-1.28)$ & 0.12 & - & - \\
\hline \multicolumn{5}{|l|}{ Self-perceived diabetic control: } \\
\hline Poor & 1 & & & \\
\hline Moderate & $2.68(0.77-9.38)$ & 0.12 & - & - \\
\hline Good & $0.91(0.30-2.75)$ & 0.86 & - & - \\
\hline Body mass index (BMI) & $1.02(0.96-1.07)$ & 0.58 & - & - \\
\hline \multicolumn{5}{|l|}{ Obesity status: } \\
\hline Not obese $(\mathrm{BMI}<25)$ & 1 & & & \\
\hline Overweight (BMI = 25-29.9) & $1.02(0.52-2.02)$ & 0.95 & - & - \\
\hline Obese (BMI $\geq 30)$ & $1.48(0.71-3.09)$ & 0.29 & - & - \\
\hline \multicolumn{5}{|l|}{ Anxiety disorders: } \\
\hline No & 1 & & & \\
\hline Yes & $1.61(0.62-4.13)$ & 0.32 & - & - \\
\hline \multicolumn{5}{|l|}{ Depressive disorders: } \\
\hline No & 1 & & & \\
\hline Yes & $1.42(0.74-2.70)$ & 0.29 & - & - \\
\hline \multicolumn{5}{|l|}{ Personality traits (BFI): } \\
\hline Extraversion & $1.16(0.72-1.86)$ & 0.55 & - & - \\
\hline Agreeableness & $0.90(0.51-1.60)$ & 0.73 & - & - \\
\hline Conscientiousness & $0.94(0.55-1.59)$ & 0.82 & - & - \\
\hline Neuroticism & $1.15(0.74-1.77)$ & 0.54 & - & - \\
\hline Openness & $1.27(0.78-2.07)$ & 0.35 & - & - \\
\hline Overall perception of QOL & $0.60(0.42-0.86)$ & $0.005^{*}$ & $0.37(0.20-0.67)$ & $0.001^{*}$ \\
\hline Overall perception of health & $0.83(0.59-1.15)$ & 0.26 & - & - \\
\hline \multicolumn{5}{|l|}{ WHOQOL-BREF scores: } \\
\hline Physical health QOL & $1.09(0.99-1.21)$ & 0.082 & - & - \\
\hline Psychological QOL & $0.95(0.84-1.06)$ & 0.35 & - & - \\
\hline Social QOL & $0.95(0.86-1.05)$ & 0.31 & - & - \\
\hline Environmental QOL & $0.95(0.85-1.07)$ & 0.38 & - & - \\
\hline
\end{tabular}

${ }^{*}$ Statistical significance at $p<0.05$. 


\section{Conclusion}

In conclusion, the prevalence of poor glycaemic control in the Malaysian diabetic population is high. A longer duration of diabetes and poor medication adherence predict poor glycaemic control, while older age and better overall perception of QOL protect against poor glycaemic control. Psychological factors, namely, personality traits and psychiatric factors, are not associated with glycaemic control in the Malaysian diabetic population. The study findings emphasize the importance of the following: (1) psychosocial interventions such as patient education and counselling, (2) the need to strengthen treatment plan for patients with longer disease durations, (3) continued evaluation of patients' perception of their QOL, and (4) consideration of biopsychosocial factors, especially in younger patients, as part of the multidisciplinary approach to the management of patients with diabetes.

\section{Data Availability}

The data used to support the findings of this study is available upon request from the corresponding author.

\section{Conflicts of Interest}

All the authors declare that there is no conflict of interest regarding the publication of this paper.

\section{Acknowledgments}

This work was supported by the Young Researcher Incentive Grant (Grant number GGPM-2019-024) from the Research University Fund of Universiti Kebangsaan Malaysia, as well as the University of Toronto Comprehensible Research Experience for Medical Students (CREMS) and Medial Alumni Association (MAA).

\section{References}

[1] World Health Organization, Global report on diabetes 2016, 2016, October 2019, https://apps.who.int/iris/bitstream/ handle/10665/204871/9789241565257_eng.pdf;jsessionid= 05EB9CC75E4628C04CA8DDBCF731AB7A? sequence=1.

[2] R. Gojka, "WHO global report on diabetes: a summary," International Journal of Noncommunicable Diseases, vol. 1, no. 1, pp. 3-8, 2016.

[3] E. Mendenhall, S. A. Norris, R. Shidhaye, and D. Prabhakaran, "Depression and type 2 diabetes in low- and middle-income countries: a systematic review," Diabetes Research and Clinical Practice, vol. 103, no. 2, pp. 276-285, 2014.

[4] N. H. Cho, J. E. Shaw, S. Karuranga et al., "IDF Diabetes Atlas: global estimates of diabetes prevalence for 2017 and projections for 2045," Diabetes Research and Clinical Practice, vol. 138, pp. 271-281, 2018.

[5] Ministry of Health Malaysia, Non-communicable diseases, risk factors and other health problems in National Health and Morbidity Survey 2015, 2015, October 2019, http://www.moh.gov .my/moh/resources/nhmsreport2015vol2.pdf.

[6] F. I. Mustapha, S. Azmi, M. R. Manaf et al., "What are the direct medical costs of managing type 2 diabetes mellitus in
Malaysia?," Medical Journal of Malaysia, vol. 72, no. 5, pp. 271-277, 2017.

[7] Ministry of Health Malaysia, National Diabetes Registry Report 2009-2012, 2013, October 2019, http://www.moh.gov.my/ moh/resources/Penerbitan/Rujukan/NCD/Diabetes/ National_Diabetes_Registry_Report_Vol_1_2009_2012.pdf.

[8] Z. Hussein, S. W. Taher, H. K. Gilcharan Singh, and W. S. S. Chee, "Diabetes care in Malaysia: problems, new models, and solutions," Annals of Global Health, vol. 81, no. 6, pp. 851862, 2015.

[9] S. Shariff-Ghazali, M. Ismail, A. T. Cheong et al., "Predictors of poor glycaemic control in older patients with type 2 diabetes mellitus," Singapore Medical Journal, vol. 56, no. 5, pp. 284 290, 2015.

[10] A. Ismail, L. S. Suddin, S. Sulong, Z. Ahmed, N. A. Kamaruddin, and N. Sukor, "Profiles and factors associated with poor glycemic control among inpatients with diabetes mellitus type 2 as a primary diagnosis in a teaching hospital," Indian Journal of Community Medicine, vol. 41, no. 3, pp. 208-212, 2016.

[11] M. H. Nini Shuhaida, M. Y. Siti Suhaila, K. A. Azidah, N. M. Norhayati, D. Nani, and M. Juliawati, "Depression, anxiety, stress and socio-demographic factors for poor glycaemic control in patients with type II diabetes," Journal of Taibah University Medical Sciences, vol. 14, no. 3, pp. 268-276, 2019.

[12] F. E. P. van Dooren, J. Denollet, F. R. J. Verhey et al., "Psychological and personality factors in type 2 diabetes mellitus, presenting the rationale and exploratory results from The Maastricht Study, a population-based cohort study," BMC Psychiatry, vol. 16, no. 17, 2016.

[13] The National Heart, Lung and Blood Institute, Managing overweight and obesity in adults: systematic evidence review from the obesity expert panel. Internet NIH Publication No. 984083, 2013, October 2019, https://www.nhlbi.nih.gov/healthtopics/managing-overweight-obesity-in-adults.

[14] American Diabetes Association, "Glycemic targets: standards of medical care in diabetes," Diabetes Care, vol. 41, Supplement 1, pp. S55-S64, 2018.

[15] R. L. Spitzer, K. Kroenke, J. B. W. Williams, and B. Löwe, "A brief measure for assessing generalized anxiety disorder: the GAD-7," JAMA Internal Medicine, vol. 166, no. 10, pp. 1092-1097, 2006.

[16] L. A. Rutter and T. A. Brown, "Psychometric properties of the Generalized Anxiety Disorder Scale-7 (GAD-7) in outpatients with anxiety and mood disorders," Journal of Psychopathology and Behavioral Assessment, vol. 39, no. 1, pp. 140-146, 2017.

[17] S. Mohd Sidik, B. Arroll, and F. Goodyear-Smith, "Validation of the GAD-7 (Malay version) among women attending a primary care clinic in Malaysia," Journal of Primary Health Care, vol. 4, no. 1, pp. 5-11, 2012.

[18] A. T. Beck, R. A. Steer, and G. K. Brown, BDI-II: Beck Depression Inventory Manual, Psychological Corporation, San Antonio, 2nd edition, 1996.

[19] F. Mukhtar and T. P. S. Oei, "Exploratory and confirmatory factor validation and psychometric properties of the Beck Depression Inventory for Malays (BDI-Malay) in Malaysia," Malaysian Journal of Psychiatry, vol. 17, no. 1, 2008.

[20] C. J. Soto and O. P. John, "Ten facet scales for the Big Five Inventory: convergence with NEO PI-R facets, self-peer agreement, and discriminant validity," Journal of Research in Personality, vol. 43, no. 1, pp. 84-90, 2009. 
[21] H. Muhamad, J. Roodenburg, and D. W. Moore, "The adaptation of the Big Five Inventory in measuring Malaysian youths' personality traits," International Journal of Advanced and Applied Sciences, vol. 5, no. 7, pp. 8-14, 2018.

[22] S. M. Skevington, M. Lotfy, K. A. O'Connel, and WHOQOL Group, “The World Health Organization's WHOQOL-BREF quality of life assessment: psychometric properties and results of the international field trial: a report from the WHOQOL Group," Quality of Life Research, vol. 13, no. 2, pp. 299-310, 2004.

[23] H. Che Ismail, L. Naing, and A. R. A. Rahman, "World Health Organization Quality of Life Assessment: brief version in Bahasa Malaysia," Medical Journal of Malaysia, vol. 58, no. 1, pp. 79-88, 2003.

[24] J. Li, K. Chattopadhyay, M. Xu et al., "Glycaemic control in type 2 diabetes patients and its predictors: a retrospective database study at a tertiary care diabetes centre in Ningbo, China," BMJ Open, vol. 8, no. 3, article e019697, 2018.

[25] L. M. Mobula, F. S. Sarfo, K. A. Carson et al., "Predictors of glycemic control in type-2 diabetes mellitus: evidence from a multicenter study in Ghana," Translational Metabolic Syndrome Research, vol. 1, no. 2018, pp. 1-8, 2018.

[26] M. F. Salem Ismail, M. M. Fares, and A. G. Abd-Alrhman, "Prevalence of depression and predictors of glycemic control among type 2 diabetes mellitus patients at family medicine clinic, Suez Canal University Hospital Egypt," World Family Medicine, vol. 17, no. 2, pp. 4-13, 2019.

[27] Y. Mamo, F. Bekele, T. Nigussie, and A. Zewudie, "Determinants of poor glycemic control among adult patients with type 2 diabetes mellitus in Jimma University Medical Center, Jimma zone, south west Ethiopia: a case control study," BMC Endocrine Disorders, vol. 19, no. 91, 2019.

[28] C. Chen, C. M. Cohrs, J. Stertmann, R. Bozsak, and S. Speier, "Human beta cell mass and function in diabetes: recent advances in knowledge and technologies to understand disease pathogenesis," Molecular Metabolism, vol. 6, no. 9, pp. 943957, 2017.

[29] A. Kamuhabwa and E. Charles, "Predictors of poor glycemic control in type 2 diabetic patients attending public hospitals in Dar es Salaam," Drug, Healthcare and Patient Safety, vol. 2014, no. 6, pp. 155-165, 2014.

[30] G. T. Demoz, A. Gebremariam, H. Yifter et al., "Predictors of poor glycemic control among patients with type 2 diabetes on follow-up care at a tertiary healthcare setting in Ethiopia," BMC Research Notes, vol. 12, no. 207, pp. S13-S27, 2019.

[31] M. Peyrot, R. R. Rubin, D. F. Kruger, and L. B. Travis, "Correlates of insulin injection omission," Diabetes Care, vol. 33, no. 2, pp. 240-245, 2010.

[32] R. Aronson, "The role of comfort and discomfort in insulin therapy," Diabetes Technology \& Therapeutics, vol. 14, no. 8, pp. 741-747, 2012.

[33] C. J. Chiu and L. A. Wray, "Factors predicting glycemic control in middle-aged and older adults with type 2 diabetes," Preventing Chronic Disease, vol. 7, no. 1, p. A08, 2010.

[34] M. P. H. S. Toh, C. X. Wu, and H. S. S. Leong, "Association of younger age with poor glycemic and cholesterol control in Asians with type 2 diabetes mellitus in Singapore," Journal of Endocrinology and Metabolism, vol. 1, no. 1, pp. 27-37, 2011.

[35] J. Barrot-de la Puente, M. Mata-Cases, J. Franch-Nadal et al., "Older type 2 diabetic patients are more likely to achieve glycaemic and cardiovascular risk factors targets than younger patients: analysis of a primary care database," International Journal of Clinical Practice, vol. 69, no. 12, pp. 1486-1495, 2015.

[36] S. M. Shamshirgaran, A. Mamaghanian, A. Aliasgarzadeh, N. Aiminisani, M. Iranparvar-Alamdari, and J. Ataie, "Age differences in diabetes-related complications and glycemic control," BMC Endocrine Disorders, vol. 17, no. 25, 2017.

[37] M. Karimy, H. R. Koohestani, and M. Araban, "The association between attitude, self-efficacy, and social support and adherence to diabetes self-care behaviour," Diabetology \& Metabolic Syndrome, vol. 10, no. 86, 2018.

[38] J. M. Cramm, M. M. Strating, M. E. Roebroeck, and A. P. Nieboer, "The importance of general self-efficacy for the quality of life of adolescents with chronic conditions," Social Indicators Research, vol. 113, no. 1, pp. 551-561, 2013.

[39] S. A. Brown, A. A. García, A. Brown et al., "Biobehavioral determinants of glycemic control in type 2 diabetes: a systematic review and meta-analysis," Patient Education and Counseling, vol. 99, no. 10, pp. 1558-1567, 2016.

[40] M. de Groot, S. H. Golden, and J. Wagner, "Psychological conditions in adults with diabetes," American Psychologist, vol. 71, no. 7, pp. 552-562, 2016.

[41] J. R. Novak, J. R. Anderson, M. D. Johnson et al., “Does personality matter in diabetes adherence?: Exploring the pathways between neuroticism and patient adherence in couples with type 2 diabetes," Applied Psychology: Health and WellBeing, vol. 9, no. 2, pp. 207-227, 2017.

[42] M. Esmaeilinasab, M. Ebrahimi, M. H. Mokarrar, L. Rahmati, M. Y. Mahjouri, and S. M. Arzaghi, "Type II diabetes and personality; a study to explore other psychosomatic aspects of diabetes," Journal of Diabetes \& Metabolic Disorders, vol. 15, no. $54,2016$.

[43] D. Waller, C. Johnston, L. Molyneaux et al., "Glycemic control and blood glucose monitoring over time in a sample of young Australians with type 1 diabetes: the role of personality," Diabetes Care, vol. 36, no. 10, pp. 2968-2973, 2013.

[44] T. C. Skinner, D. G. Bruce, T. M. Davis, and W. A. Davis, "Personality traits, self-care behaviours and glycaemic control in type 2 diabetes: the Fremantle Diabetes Study Phase II," Diabetic Medicine, vol. 31, no. 4, pp. 487-492, 2014.

[45] A. S. Phillips and C. A. Guarnaccia, "The five-factor model of personality and self-reported versus biomarker diabetic control," Journal of Health Psychology, vol. 21, no. 10, pp. 23282338, 2016.

[46] J. P. A. Ioannidis, "Why most published research findings are false," PLoS Medicine, vol. 2, article e124, 2005.

[47] C. J. Patel and J. P. Ioannidis, "Placing epidemiological results in the context of multiplicity and typical correlations of exposures," Journal of Epidemiology and Community Health, vol. 68, no. 11, pp. 1096-1100, 2014.

[48] K. J. Rothman, "No adjustments are needed for multiple comparisons," Epidemiology, vol. 1, no. 1, pp. 43-46, 1990. 